\title{
Estrategias para (no) olvidar: notas sobre dos documentales chilenos de la post-dictadura
}

Strategies for (Not) Forgetting: Notes on Two Chilean Documentary Films of the Post-Dictatorship

\section{Elizabeth Ramírez}

University of Warwick

elizabethramirezs@gmail.com

Resumen • El retorno de la democracia originó un número creciente de documentales interesados en mantener viva la memoria de la dictadura. Aunque tradicionalmente caracterizados por su compromiso social, los documentales recientes han preferido en cambio, centrarse en mundos privados. A través de relatos autobiográficos, la generación de la post-dictadura desarrollará nuevos modos expresivos para referirse a este trauma cultural. Este artículo analizará dos documentales recientes -Remitente: Una Carta Visual (2008) y La Quemadura (2009)-para explorar las estrategias que los realizadores adoptan para entrelazar sus reflexiones personales sobre memoria e identidad con la experiencia colectiva de la dictadura. A pesar de no ser precisamente narraciones de 'segundas generaciones' buscan desde la 'post-memoria' dar cuenta del pasado reciente y exhibir sus ruinas en el presente.

Palabras clave: dictadura, trauma cultural, post-memoria, documental, autobiografía.

Abstract • The return to democracy saw a growing number of documentary films interested in keeping the memory of the dictatorship alive. Although traditionally characterised by their commitment to social issues, recent documentaries shifted to narratives centered on the private sphere. Through autobiographical stories, filmmakers of the post-dictatorship generation have developed new expressive ways to refer to this cultural trauma. This article focuses on two recent films-Postage: $A$ Visual Letter (2008) and The Burn (2009)- to explore the different strategies that filmmakers adopt to merge their personal reflections on memory and identity with the collective experience of the dictatorship. Although not precisely 'second generation' accounts, they will be understood as 'postmemory' narrations that critically address the recent past and exhibit its remnants today.

Keywords: Dictatorship, Cultural Trauma, Postmemory, Documentary, Autobiography. 
Las diversas "irrupciones de memoria" (Wilde, 1999) que han tomado por asalto el espacio público chileno en el último tiempo, como la polémica inauguración del Museo de la Memoria y los Derechos Humanos, el féretro de Víctor Jara recorriendo las calles de Santiago y los bustos de Pinochet que hicieron circular por la misma ciudad simpatizantes de la derecha para celebrar la caída de la Concertación después de veinte años de gobierno consecutivo, demuestran no sólo que la sociedad chilena permanece dividida por el pasado dictatorial sino que este pasado tiene imbricadas formas de hacerse presente.

Los documentalistas chilenos han registrado incansablemente este pasado y sus resabios en la actualidad. Nuevas generaciones de realizadores se han unido a las que, desde la década de los sesenta, han documentado las profundas transformaciones experimentadas por la sociedad chilena, desde la ilusión del proyecto socialista, su derrumbe y la arremetida de un sistema neoliberal sin precedentes. Con ellas emergerán nuevas maneras de hacer memoria y de representar el pasado.

A través del análisis de los documentales Remitente: Una carta visual (Chile, 2008, 18 min.) de Tiziana Panizza y La Quemadura (Chile-Francia, 2009, 65 min.) de René Ballesteros ${ }^{1}$ el presente artículo busca dar algunas luces sobre los modos de recordar de una nueva generación de documentalistas. Ésta, lejos de la grandilocuencia y de los discursos militantes, adopta, desde la esfera privada, diversas estrategias audiovisuales para reflexionar sobre la memoria y su fragilidad y evocar el trauma cultural de la dictadura de Augusto Pinochet (1973-1990).

Además de remitirnos a la dictadura a través de desvíos expresivos, en especial, a través de sus ruinas en el presente, estos documentales tienen en común haber sido realizados por documentalistas nacidos en Chile en los setenta, con formación en el extranjero, y haber sido producidos con la ayuda de fondos estatales. Esto último, lejos de significar restricciones para los realizadores, da cuenta de la incipiente institucionalización del documental nacional en la última década, en contraste con su condición marginal previa. Sus realizaciones, por lo tanto, nos permitirán reflexionar sobre cómo recuerda una generación que se mueve dentro un mundo altamente interconectado, cuáles son las estrategias que utiliza para dar cuenta de la existencia de un pasado histórico del que no fue protagonista y de la imposibilidad de representarlo, y cómo problematiza, desde esta perspectiva, los conceptos de memoria e identidad.

René Ballesteros estudió cine en la Escuela de Cine y Televisión de (EICTV) de San Antonio de los Baños (Cuba) y en la Universidad de París (Francia). Actualmente es residente en Le Fresnoy, Studio National des Arts Contemporaines (también en Francia), instituto que actuó como co-productor de La Quemadura. En ésta, su ópera prima, el realizador intenta en vano descubrir las razones del abandono de su madre hace 26 años y al mismo tiempo busca reconstituir, junto a su hermana archivista y bibliotecóloga, la historia de la editorial Quimantú, surgida bajo el gobierno de la Unidad Popular, que se entrelaza de alguna manera con la historia de su madre.

Tiziana Panizza es ítalo-chilena y también tiene estudios de cine en la EICTV y en la Universidad de Westminster (Inglaterra). Remitente es el segundo documental experimental de la trilogía Cartas Visuales iniciada en Londres, en la cual la realizadora retoma el hábito de escribir cartas que cultivó cuando niña influenciada por su abuela, quien solía escribir

La Quemadura recibió el premio Joris Ivens en la última versión del Festival Internacional de Documentales Cinéma du Réel 2010 (Francia) y espera pronto estreno en salas nacionales, mientras que Remitente fue la gran ganadora cartas a sus familiares en Italia. Al igual que La Ouemadura, este documental es una reflexión sobre la memoria y sus artificios, pero mientras la realización de Ballesteros está hecha en soporte digital (como la mayor parte de la producción documental nacional contemporánea), Remitente está filmada en súper 8, el formato que antaño adquirían las grabaciones caseras, por lo que hay aquí un interés más palmario en explorar la materialidad del recuerdo.

Antes de analizar cuáles son las estrategias que específicamente adoptan Remitente y La Ouemadura para evocar el pasado reciente del país, nos referiremos a los modos de recordar de la generación de la post-dictadura, la cual, lejos de los discursos militantes de antaño, se caracteriza por adoptar un tono afectivo e imaginativo para intentar reflexiona sobre la experiencia dictatorial. Posteriormente, se intentarán delinear las razones de la emergencia de documentales centrados en la esfera privada, relacionadas con la desaparición de la figura del sujeto popular y colectivo tras la llegada de la democracia, para finalmente enfocarnos en los particulares relatos autobiográficos de estos realizadores.

\section{LA MEMORIA DE LA DICTADURA Y LAS NUEVAS GENERACIONES}

El interés por la memoria en el documental chileno actual surge en un momento donde la preocupación por esta temática ha desbordado ampliamente los límites académicos y artísticos, convirtiendo a la sociedad occidental contemporánea en lo que Andreas Huyssen (2000) ha denominado una "cultura de la memoria". En América Latina este interés ha sido esencialmente político, y busca reflexionar sobre los efectos de las dictaduras durante las transiciones ${ }^{2}$ y al mismo tiempo, lograr justicia y reparación, particularmente, para las víctimas directas como los torturados, los desaparecidos y sus familiares (Jelin, 2001). No es gratuito, por lo tanto, que conceptos como trauma, duelo y melancolía sean recurrentes en la literatura que surge en este período como han señalado diversos autores (Richard, 2000: 273; Avelar, 2001: 253).

Ante las diversas catástrofes (humanas y naturales) que ha experimentado la sociedad contemporánea, el concepto de trauma se ha extendido más allá del individuo, lo que permite escribir a la teórica de cine E. Ann Kaplan, influenciada por su propia experiencia del 9/11, que "las interconexiones entre trauma individual y colectivo son tales, que parece imposible determinar dónde empieza el 'yo' y dónde terminan las reacciones culturales" (Kaplan, 2005: 2) ${ }^{3}$. Para la autora, las sociedades también pueden sufrir traumas y olvidar las atrocidades del pasado.

A pesar de que reconoce que los traumas culturales no son recordados al igual que uno psicológico, Kaplan afirma que: "el impacto de los crímenes pasados en un estadonación puede evidenciarse en la forma de 'síntomas' culturales de un modo similar que en los individuos traumatizados" ${ }^{4}(68)$. Si entendemos la experiencia de la dictadura militar

La transición será entendida aquí no sólo como el retorno a un sistema democrático sino también, como nos explica Idelber Avelar (2001) siguiendo a Willy Thayer, como el término que designa el paso del estadonación al mercado global que se gestó durante las dictaduras de la región (en países como Chile, Argentin o Brasil). La transición, por lo tanto, es un períido que amenaza con permanecer.
"The complex interconnections between individual and cultural trauma (are) "self' begins and cultural reactions end may seem impossible to determ".

"The impact of past crimes in a nation-state may evidence itself in the form of cultural 'symptoms' analogous to those in individuals" [traducción del autor]. 
como un evento traumático ¿o acaso las "irrupciones" de las que nos habla Wilde no son parte del pasado que regresa a atormentar a los chilenos? el concepto de post-memoria desarrollado por Marianne Hirsch (1997) resulta particularmente útil para comenzar a entender las realizaciones de la generación de la post-dictadura.

Lejos de sugerir que hay algo después de la memoria, con la noción de post-memoria la autora busca señalar la distancia temporal que existe entre la experiencia traumática y las nuevas generaciones que no la vivieron directamente, a la vez que subrayar el fuerte vínculo emocional que las une a ésta, alejándolas así de la historia (de la historia como evento). Post-memoria, dice Hirsch: "es un tipo de memoria poderosa y muy particular, precisamente porque la conexión con su objeto o fuente es mediada no a través del recuerdo, sino a través de una inversión imaginativa y creativa" ${ }^{5}$ (1997: 22). Aunque usado inicialmente para explicar los modos de recordar de las "segundas generaciones"-hijos e hijas de las víctimas directas del Holocausto- Hirsch extiende posteriormente el concepto para entenderlo no sólo como una posición esculpida por la identidad sino como un "espacio de recuerdo" (space of remembrance) cultural y sobre todo, como una postura "ética" de identificación con el "otro" que ha sufrido la experiencia del horror (1999: 8-9).

Resulta útil, por lo tanto, recurrir a esta categoría en tanto enfatiza la dimensión ética de recordar, mientras ilumina las diferencias del trabajo de la memoria (la memoria como acto, como trabajo productivo) entre los documentalistas que vivieron directamente la tiranía de Pinochet y hoy la recuerdan (como por ejemplo, Patricio Guzmán, Patricio Henríquez o Gastón Ancelovici) y aquellos que no la vivieron directamente pero que han crecido bajo su sombra durante la post-dictadura (como los realizadores aquí analizados).

La noción de post-memoria ha sido utilizada en el contexto latinoamericano, para el análisis de documentales argentinos recientes que evocan el pasado dictatorial, aunque casi exclusivamente para referirse a aquellos realizados por hijos e hijas de víctimas de la dictadura en ese país ${ }^{6}$. Esta "segunda generación" de documentalistas, donde destacan, por ejemplo, Nicolás Prividera con $M$ (2007) y especialmente, Albertina Carri con Los Rubios 2003), ha desarrollado arriesg categorías de identidad, memoria e historia. Al respecto de sus trabajos afirma Ana Amado ${ }^{7}$ :

haciendo caso omiso al discurso público oficial, las nuevas generaciones han elegido el discurso de las emociones por sobre el de las estridentes proclamaciones políticas que han caracterizado a la generacion de sus padres, evidente en los documentales de los 60s y la mitad de los $70 s^{8}(2009 / 2010: 38)$

Este giro afectivo y subjetivo en la representación de la atrocidad puede ser observado también (aunque en menor medida) en una 'segunda generación' de realizadores chilenos,

"Postmemory is a powerful and very particular form of memory precisely because its connection to its object or source is mediated not through recollection but through an imaginative investment and creation" [traducción del autor

(2005) y de Michael J. Lazzara (2009). Este úl por

列 "Disregarding the contempory public discourse, the youner precisamente el término de post-memoria. emotions instead of the strident political pronouncements that characterized their parents' generation, as evident in the documentary films made in the 60s and in the first half of the 70s in Argentina." [traducción del autor] como es el caso de En algún lugar del cielo (2003) de Alejandra Carmona, donde la realizadora busca reconstruir la historia de su padre, periodista y militante asesinado durante la dictadura, y al mismo tiempo reflexionar sobre su propia identidad como chilena criada en el exilio, o de Lo que recordarás de septiembre (2004) de Cecilia Cornejo quien desde el Nueva York post 9/11 narra la historia de sus padres que vivieron la represión y posteriormente partieron al exilio.

La noción de post-memoria será extendida aquí más allá de las narraciones de los hijos e hijas de las víctimas directas de la represión y nos permitirá reflexionar acerca de los modos de recordar de realizadores que, dejando de lado el tema de la violación a los derechos humanos, tan presente en el repertorio documental de la post-dictadura, logran articular a través de otros desvíos, un discurso crítico sobre el pasado y sus residuos en la sociedad chilena actual.

\section{EL DESVANECIMIENTO DE LO COLECTIVO, LA EMERGENCIA DE LOS MUNDOS \\ PRIVADOS}

La Quemadura y Remitente constituyen sólo una muestra dentro de la proliferación de narraciones de carácter autobiográfico o, más ampliamente, dentro del giro hacia los mundos interiores, que en América Latina tiene sus orígenes en el regreso de los regímenes democráticos (Chanan, 2003; Rich, 1997). Como explica Michael Chanan, este retorno significó una crisis para el cine documental en la región, no simplemente en términos económicos, ya que las organizaciones extranjeras que solidarizaban con la causa chilena por la recuperación de la democracia dejaron de financiar sus producciones, sino especialmente en términos de identidad. "Para un cine fundado en una concepción política de sí mismo [...] la transformación del espacio político en el que operaba como un resultado del cambio democrático de los ochenta, amenazó con dejarlo a la deriva” (2003: 30).

En Chile, según Tomás Moulián (2002), esta transformación consistió, a grandes rasgos, en una "desideologización" de la política provocada por una democracia basada en el discurso oficial del consenso y reconciliación, que ha tenido como principal objetivo la perpetuación del sistema neoliberal instaurado durante la dictadura militar de Pinochet. Durante este proceso, se reemplazó la figura del ciudadano por la del consumidor y se terminó de sepultar la figura del pueblo, tan alicaída luego del fracaso de la Unidad Popular y del desencanto que ha caracterizado la transición.

El pueblo y la acción colectiva de grandes masas, protagonistas indiscutidos de los documentales de las décadas anteriores, rápidamente se desvanecerían. Explica Francine Masiello (2001: 23-24) que la figura de "lo popular" adquirirá en las transiciones un carácter altamente conflictivo para los intelectuales y artistas de la región. Ya que si bien es el interés por el sujeto popular lo que tradicionalmente ha distinguido a la teoría latinoamericana en el orden mundial, al interior, esta categoría obtendrá una connotación añeja y sospechosa luego de la caída de los proyectos revolucionarios. De este modo, las nociones del sujeto popular o de pueblo, serán reemplazadas por otras categorías políticas y estéticas, especialmente la de género (15).

Profundamente influenciada por la noción de "devenir mujer" del teórico Néstor Perlongher, Masiello lejos de entender lo femenino como una esencia biológica o elección sexual, lo hace como un accionar desde los márgenes, desde los intersticios de los discursos hegemónicos. En este sentido, la perspectiva de género permite, para la autora, cuestionar 
la idea fija de identidad, entendiéndola como tránsito permanente y generar quiebres en las representaciones promovidas desde las voces oficiales (39-40). Así, estos documentalistas se mueven sin grandes aspavientos por diversos países e idiomas, por ejemplo, y a través de estos desplazamientos no sólo negocian las representaciones del "ser chileno" sino también los límites del documental, fragmentando sus relatos, exhibiendo su construcción, enfatizando la imposibilidad de la existencia de una única versión del pasado.

A la luz de estas radicales transformaciones políticas y socio-culturales, el documental chileno supuso no un abandono de la temática de la dictadura y de sus consecuencias, pero sí, dice Jacqueline Mouesca, un necesario cambio de mirada (2005: 134). El cine urgente y de "trinchera" de las décadas anteriores dio paso a documentales que buscaban informar sobre el periodo dictatorial, especialmente sobre los abusos perpetrados por los militares, los que eran construidos, en su mayoría, sobre la base de testimonios de sobrevivientes y familiares de las víctimas de los detenidos desaparecidos.

Al mismo tiempo, sin embargo, surgirían las narraciones de tono más reflexivo e intimista, articuladas desde el "yo", por realizadores que estuvieron involucrados de alguna u otra manera en la lucha política de los setenta. En sus documentales buscarían establecer vínculos entre la memoria individual y la colectiva como es evidente en $\mathrm{La}$ Flaca Alejandra (1993) de Carmen Castillo y, algunos años más tarde (aunque todavía con un gran interés en la figura de lo colectivo) Chile, La Memoria Obstinada (1997) de Patricio Guzmán.

La ausencia de la noción de pueblo se hará cada vez más evidente en los documentales de la generación de la post-dictadura, quienes a pesar de mantener el interés en el régimen militar y las transformaciones que éste produjo en la sociedad chilena, preferirán las historias mínimas, enfocándose en las repercusiones que éste provocó en la vida del ciudadano común'. En muchas de estas narraciones, el desvanecimiento de lo popular irá de la mano con la representación oblicua que ha adquirido la memoria en este último tiempo, y que surgiría como alternativa al binarismo olvido/memoria y como contra-discurso ante sobreabundancia de las imágenes de la atrocidad durante la conmemoración de los treinta años del golpe militar (Pinto, sin fecha).

De este modo, la imagen del "pueblo" como actor político y gestor de una épica mayor en el documental chileno de las décadas sesenta y setenta, ha desaparecido en el desencanto de esta transición que amenaza con quedarse para siempre, siendo desplazada por historias mínimas de figuras fantasmales, perplejas y desmemoriadas. Las representaciones que adquirirá el habitante de la post-dictadura serán entre otras, la de la figura espectral, violentada por un pasado político inconveniente de recordar (como por ejemplo, en La Sombra de Don Roberto (2007) de Juan Diego Spoerer o en Por Sospecha de Comunista (2008) de Cristóbal Cohen y Marcelo Hermosilla), la de una figura perpleja ante las rápidas transformaciones de la ciudad, desmovilizada y despojada de poder En defensa propia (2009) de Claudia Barril y La Batalla de Plaza Italia de Renato Villegas (2008) o la de aquella que ha perdido la capacidad de recordar (Reinalda del Carmen, mi mamá y yo (2007) de Lorena Giachino, y en los documentales aquí analizados).
Para Chanan (2003: 23), el giro hacia los mundos privados, especialmente el boom del relato autobiográfico, está marcado no sólo por la transformación de la visibilidad provocada por la televisión y los reality shows por ejemplo, sino también por lo que el autor denomina una "tendencia al narcisismo" de los documentalistas independientes al buscar retratar sus propias vidas y las de sus familiares. Sin embargo, cuando los documentales buscan problematizar los límites entre las esferas públicas y privadas, cuando buscan vincular lo íntimo con lo social, poniendo en práctica el recurrente lema feminista de que "lo personal es político", se acercan más a lo que la crítica cultural Annette Kuhn (2002) ha denominado "autobiografías revisionistas" (revisionist autobiographies). Este tipo de narración, en el cual podemos localizar los documentales de Panizza y Ballesteros, se opone a la autobiografía tradicional ya que no sólo no se centra en la vida de un individuo en particular, sino que, al contrario, busca recorrer las interconexiones entre lo personal y lo público, las imbricaciones entre la "experiencia y la historia" (151).

Aquí las memorias individuales van mucho más allá de la esfera privada y establecen complejas interconexiones entre la historia familiar y la nacional, que estos textos buscan hacer visibles. En las autobiografías revisionistas, nos dice Kuhn, no sólo el concepto de identidad sino también el de memoria son puestos en crisis. Para la autora, la identidad, más allá de ser entendida como proceso, pasa a ser una construcción de las distintas estructuras sociales en juego, como la de género o la generacional en este caso. La autenticidad de la memoria y sus "evidencias", donde el mejor ejemplo son las fotografías de familia (veremos cómo Ballesteros no dudará en calificar las fotos de su infancia como de "ficción", o como Panizza no dudará en hacer suyas memorias de otros), serán también profundamente cuestionadas por este tipo de relato (2002: 150-153). Ya no se trata, por supuesto, de la memoria como verdad (los conceptos de verdad y objetividad son de hecho permanentemente problematizados), ni se recurre a ésta ni en consecuencia, a la identidad (si es que lo que nos constituye como individuos es aquello que recordamos) para dar testimonio de un hecho irrefutable, sino para exhibir sus fisuras, para mirarla con sospecha.

Tanto La Quemadura como Remitente se plantean desde un comienzo como relatos mínimos y abiertos, domésticos y subjetivos, pero al mismo tiempo, complejamente entrelazados con la historia de la nación que los cruza. La relación con este pasado es, sin embargo, explícitamente mediada por un narrador en primera persona que hace manifiesta su presencia detrás de las cámaras y frente a éstas, ya sea como relator o personaje. Estos documentales buscan, por lo tanto, dar cuenta de la imposibilidad de la representación del pasado y de la objetividad (lo que hacen especialmente a través del despliegue del carácter frágil e incierto de la memoria), por lo que, siguiendo a Stella Bruzzi (2000), pueden definirse como "documentales performativos".

Los documentales performativos se caracterizan por reconocer que están construidos sobre la base de la "interacción entre performance y realidad" (el documental existe porque hay alguien que está filmando) y por exhibir su condición de "construcción y artificialidad" (al contrario que el documental más convencional de "cine directo" que se caracteriza por ocultar la intervención del realizador) (154). A través de esta estrategia que busca, según la autora, distanciar la obra del espectador, los documentales aquí analizados nos exigen una participación activa y crítica, dejando preguntas sin respuestas, construyéndose sobre las ausencias, invitando a reflexionar sobre la imposibilidad de recuperar este pasado porque, como dice la madre de Ballesteros, "lo pasado pasado. No se le puede dar la vuelta atrás a nada”. 


\section{LA QUEMADURA: SOBRE LOS SECRETOS DE FAMILIA}

Una de las frases dichas por Panizza en su documental, "si el recuerdo es una imagen, el olvido debe ser la ceguera, el exceso del ruido y de luz" "10, nos entrega algunas pistas sobre el documental de Ballesteros. ¿Cómo apropiarse de un pasado del que uno no ha sido protagonista, pero del que inevitablemente se reciben los coletazos? ¿Cómo referirse a la historia familiar si no existen versiones muy claras de lo que sucedió, si nadie quiere o puede hablar, si todo ha devenido olvido o secreto?

El realizador de La Quemadura vuelca su mirada hacia el pasado familiar y hacia el abandono de su madre para hablar de las ausencias, la fragilidad de la memoria, el pasado familiar y sus restos, vinculándolos al trauma de la nación chilena. En su narración no hay voice over, pero la figura del director se hace presente como realizador-personaje, aunque nunca como uno autoritario. Al contrario, su presencia adquiere la representación de una figura escindida, mostrada de espaldas, fragmentada dentro del agua, o sólo como voz tras la cámara que graba, por ejemplo.

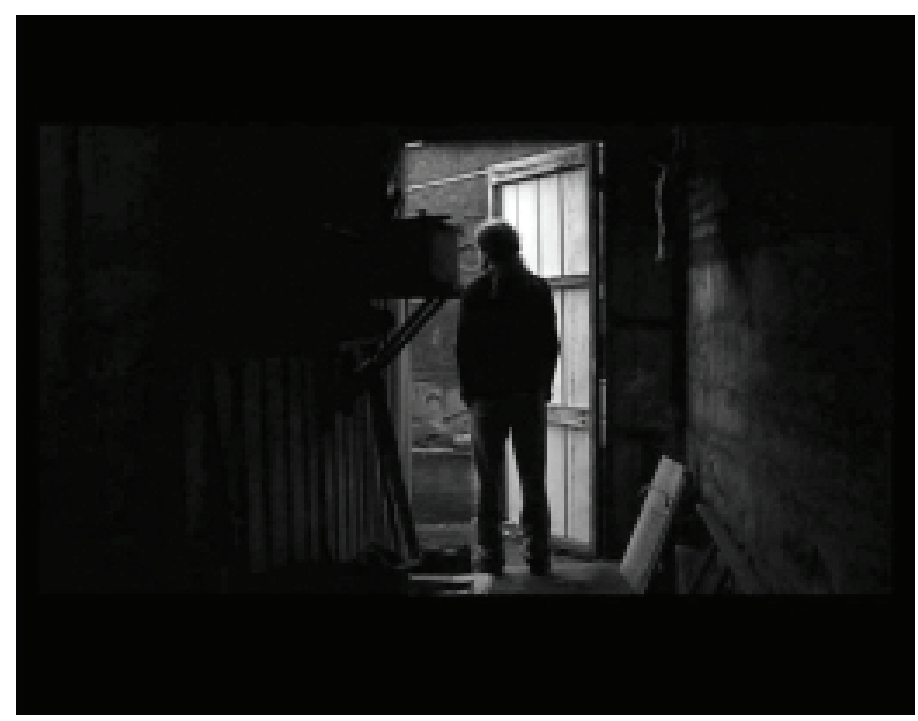

La Quemadura.

Estableciendo un paralelo entre la labor de documentalista (el realizador), de archivista (su hermana, que realiza a su vez una investigación sobre el rol que jugó la editorial Quimantú en la masificación del libro) y la de una suerte de arqueólogos de la modernidad (ambos), el realizador desplegará ante la cámara su intento fallido de rescate tanto del pasado familiar como de los libros de la popular editorial del gobierno de Salvador Allende, ambos perdidos para siempre.

10 "If memory is an image, forgetting should be blindness, excess of noise and light" [traducción del autor].
Es precisamente a través de los libros de la madre, de libros que no le pertenecen, de "libros desaparecidos" (como les llaman los hermanos Ballesteros) que el recuerdo de este pasado común se hace presente en el documental y que se extiende aún más allá del secreto de familia, volviéndose así-los libros de Quimantú- una suerte de secreto nacional. De este modo, Ballesteros no sólo está interesado en exponer la pérdida de memoria de su abuela (a causa del Alzheimer) y de su madre (a causa de un "shock" como dice ella, trauma que permanecerá como secreto familiar) sino de vincularlas explícitamente a la desaparición de los libros y al olvido de este pasado cultural que los ha relegado a librerías de segunda mano, condenando la antigua editorial a la desaparición.

El suyo es un proyecto fallido desde un comienzo porque hay indefectiblemente una parte de la historia privada y colectiva que se perdió para siempre. La gente no quiere o no puede hablar: la abuela está enferma y confunde en sus recuerdos la figura de su hija con la de su madre constantemente, el padre del realizador se niega a hablar del abandono de la madre "yo no creo que eso sea un tema para poner en un documental", le dice a su hijo. La madre se presenta reacia a hablar en un principio y responde "pregúntale a tu abuela", pero muy pronto nos daremos cuenta que ella no habla no tanto porque no quiera, sino porque no recuerda, porque todo lo ha olvidado.

No hay salida, no hay entrada a estos entramados de la memoria. Por eso es que el relato es circular (el relato comienza con la ausencia de una imagen, la pantalla en negro, y la interrupción de la imagen por el sonido, y finaliza igual, con los susurros de los hermanos, quienes vuelven a recordar, a hablar de la memoria sobre el fondo negro). El realizador pide algunas explicaciones, pero no hay rencor ni acusaciones en su búsqueda. El documentalista aparece, aunque persistente, más bien perplejo, confundido, por lo que no hay urgencia aquí, no hay apuro, el ritmo del documental es pausado aunque agobiante, los planos son cerrados y de larga duración. Nunca entendió muy bien por qué la madre se fue, por qué nadie habló más de este pasado que se convirtió en fantasma. No lo entenderá tampoco durante el documental, la verdad siempre se escurrirá. Aquí sin embargo, no es la verdad lo que está en juego, sino la acción de preguntar, de dejar esta pregunta abierta y de poner en escena la ausencia y el olvido, evidenciando los desvíos que requiere la representación del pasado.

Es a través del sonido de la lluvia que el realizador abre su narración, sonido que se funde luego con la voz en off de una mujer al teléfono que hace preguntas superficiales y algo extrañas (“¡tú eres gordo? ¿tienes barriga? ¿eres flaco liso?”) mientras la pantalla permanece negra. El realizador parece desconcertado, de ahí el relato fragmentado y elíptico, los desplazamientos geográficos sin explicación y sin ser avisados, la duda acerca de la legitimidad de los recuerdos (por ejemplo, confunde los sueños con los recuerdos, no está cierto de si él borró o no el nombre de su madre de los libros), pero está empeñado en comprender la partida de su madre. El enigma de la identidad de la mujer de la voz en off se resolverá luego, el espectador comprenderá pronto que esa desconocida es la madre.

Sin embargo, su ausencia continuará a lo largo del documental. Es de hecho, esta ausencia la que guía su construcción y la madre permanecerá como una "presencia fantasmagórica, invisible" (Ballesteros en Borghino, 2010). Su presencia en la narración sólo dará cuenta de su falta, ya que ella se configurará únicamente a través de una voz sin cuerpo al teléfono contra una pantalla negra, sobrepuesta a imágenes de Ballesteros aprendiendo a nadar (el agua como cura a la quemadura, a la herida) o del realizador caminando en el campo, en el sur de Chile. La madre permanecerá incorpórea incluso cuando ellos la visiten después de más de veinte años, ya que el realizador no registra el encuentro familiar en Venezuela, 
eliminándolo de la narración. Es a través de la elipsis de este momento fundamental, que se enfatiza la pérdida y la imposibilidad de reconciliarse con el pasado: la madre no puede ser representada, y se verá sólo parcialmente al final cuando ella se reencuentre con su propia madre. Sólo una parte de ella, ya que, la paradoja de este gran final es que el encuentro entre las madres, el clímax del documental, por así decirlo, queda oculto tras diversos cuerpos (los hijos, los nietos). Al querer ver se opone la imposibilidad de hacerlo. No, el pasado no se puede representar, más que a través de sus contornos.

Para Ballesteros es tan importante dar cuenta de esta imposibilidad como la de la precariedad y los artificios de la memoria. Esto queda de manifiesto en la escena en que mira las fotos polaroid de él y de su hermana cuando niños que su madre les regaló luego de la primera reunión familiar y que él ve como una puesta en escena su madre. Las polaroid -él con corbata, ella con vestido, caminando por la calle del barrio, sentados sobre el capot del auto, en fin, escenas de la vida cotidiana- son enfocadas en un primer plano pero siempre hay una parte de ellas que no se pueden ver, uno de los hermanos la cubre con su silueta, volviéndolas más difusas.

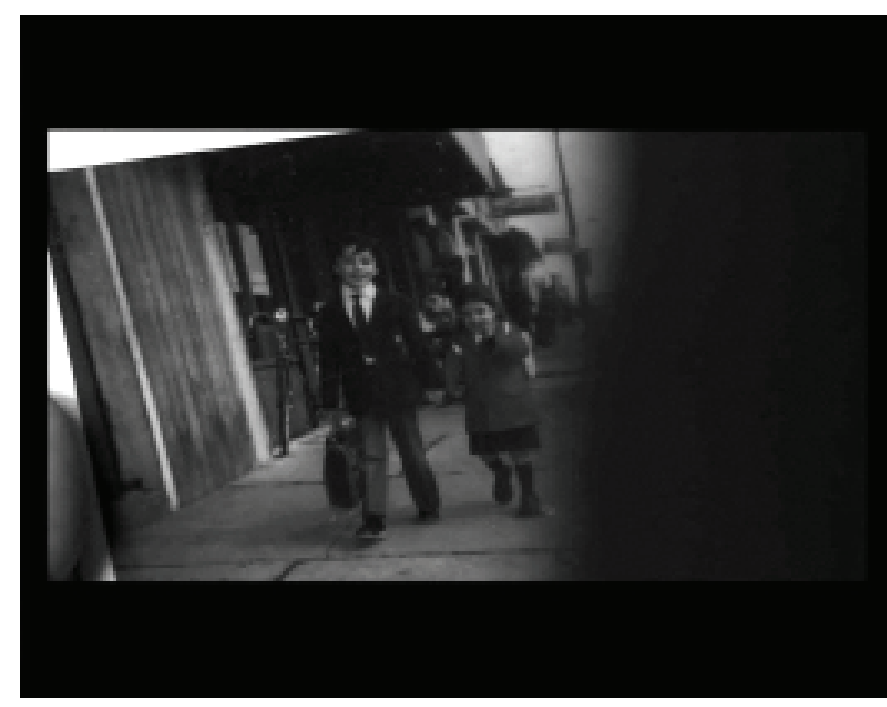

La Quemadura 2.

En voz en off se escucha a Ballesteros un poco desconcertado, cree que la madre al deshacerse de las fotos, se está despidiendo de ellos. Su hermana Karin le pregunta cuáles son las que le gustan más:

René: ¿Las que me gustan más?... Es que éstas parecen como de mentira yo encuentro... Karin: Sí... En todas aparecemos sonriendo... En todas aparecemos así como...

René: ... Ella me dijo que las fotos las tomó, las polaroid, una semana antes de irse a Venezuela. Nos hizo que nos cambiáramos de ropa para que saliéramos con la mejor ropa que teníamos. Es como una ficción.

Esta escena ilustra diversos puntos señalados por Kuhn, tales como que las fotos familiares (y las imágenes en general) pueden ser un campo de batalla, que esta batalla se lleva a cabo en el presente por mucho que las fotos estén tomadas en un pasado remoto, que es el "uso" que les da aquél que las lee lo que pone en tensión el ayer y hoy. Margarita, la madre, sabía antes de tomarlas el valor que éstas tendrían, sabía que serían compartidas, que podrían cumplir lo que las fotos de familia prometen, "la promesa es la de un pasado más luminoso en el futuro"11 como nos dice Kuhn (2002: 23). Ballesteros descubre en el presente el elemento de fabricación, de ficción en ellas. Los hermanos leen a través de los vestidos y las sonrisas, que aquél era el tiempo anterior al abandono. Es el grado de construcción de la memoria, la sospecha que genera (¿cómo construimos el pasado si no creemos en las imágenes, si desconfiamos de ellas?), la que es puesta en evidencia aquí.

Volvamos a los libros, ya que son los libros los que funcionan como puente con el pasado familiar e histórico. El realizador visita con su hermana el sitio donde se encontraba la editorial junto con dos ex trabajadores de la empresa estatal. Completamente destruido, el lugar no es más que una ruina que espera la construcción de uno más de los miles de proyectos inmobiliarios que inundan la capital. La imagen del Santiago del progreso que ha comenzado a invadir los documentales actuales desde el fundamental Aquí se construye (2000) de Ignacio Agüero -quien establece un paralelo entre la destrucción del patrimonio arquitectónico y el entierro de las huellas del pasado reciente bajo el avance vertiginoso del neoliberalismo- es la misma que la de la destrucción de la memoria.

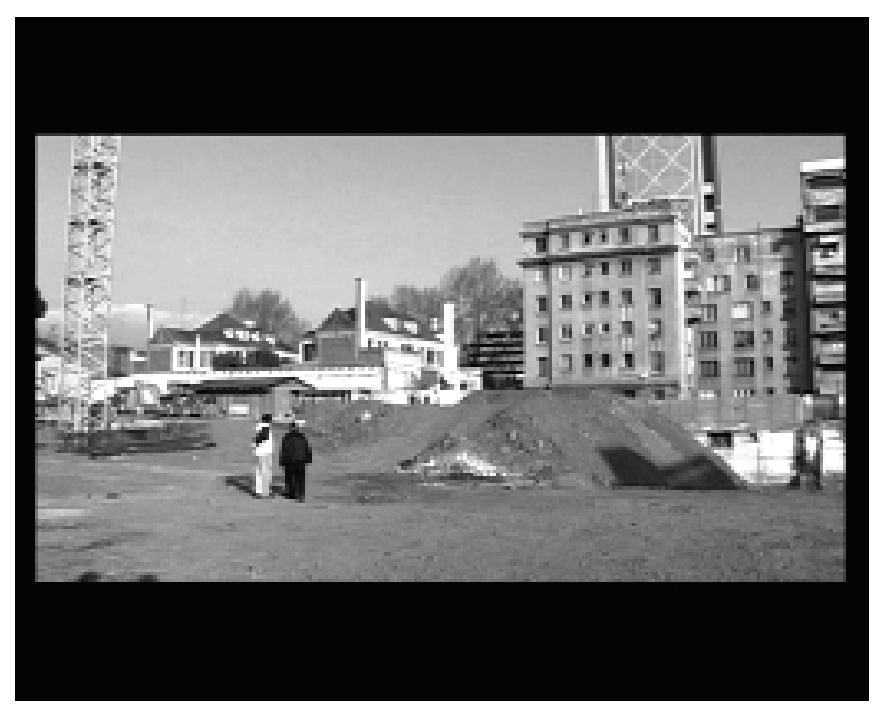

La Quemadura 3.

El título La Quemadura, no sólo connota la marca del abandono de la madre, sino que también es una referencia a la gran fogata donde los militares quemaron los libros de la editorial Quimantú en los días posteriores al golpe de estado. Es precisamente en esta escena donde se pone en tensión abiertamente lo personal con lo público. Es el interés por los libros de esta casa editorial que la madre coleccionaba (y que ahora tampoco recuerda)

11 "The promise is of a brighter past in the future" [traducción del autor]. 
lo que llevó a los hermanos a este terreno baldío. Los libros que han desaparecido, tanto de su casa como de la historia del país, dejando sólo algunos rastros esparcidos por ahí, son el único vínculo que tienen tanto con su madre como con el pasado dictatorial. Se entrecruzan aquí la memoria individual de los hermanos y la de los trabajadores, la memoria de la historia familiar de los Ballesteros con la de la historia del país, mientras el fantasma de los libros de la Unidad Popular, de un pasado común, se hace presente en el vacío de este terreno "en construcción". El realizador ve este entretejido "como muestras, en el sentido de las muestras médicas, como un análisis microscópico de un momento en la historia de una familia que pudiera iluminar un fragmento de la historia de la censura y destrucción de libros en Chile" (Ballesteros, entrevista personal, 2010).

Nuevamente, este pasado no es representado sino a través de su ausencia. Aquí no hay imágenes de archivo del tiempo de gloria de la editorial Quimantú, tampoco las hay de la represión ni de la fogata, ni de La Moneda en llamas. Es a través de los silencios y las dudas, que este pasado se filtra en los testimonios de los únicos personajes que no son parte de la familia Ballesteros. Las entrevistas a los ex trabajadores le sirven también al realizador (y al espectador) para volver a desconfiar de la memoria.

De hecho, para el realizador, la convergencia entre las esferas públicas y privadas tiene que ver con "un vínculo, sobre todo, en la censura y la autocensura. Y la censura es tanto hacia el otro, hacia el nombre o la evocación de otra persona como hacia sí mismo, a partes de la propia biografía" (Entrevista personal). Mientras uno de los trabajadores dice que los libros simplemente se perdieron, "pero no es que los hayamos hecho tira", el otro lo interrumpirá para contar que los libros no están porque muchas personas se deshicieron de ellos a causa del miedo, y muchos de ellos fueron quemados o tirados por respiraderos para que los militares no los encontraran, exhibiendo así no sólo las versiones contradictorias del pasado que emergen en el presente y el carácter vulnerable de la memoria, sino también el temor que se cuela a través de los recuerdos de estos hombres.

Así, el realizador va construyendo este relato a partir de los intersticios, no sólo narrando su historia desde la periferia -desde una familia desecha, desde su micro-historia, desde una generación sin grandes épicas que narrar, desde localidades no metropolitanas- sino que además fundiéndose en un universo puramente femenino (su relato es protagonizado por mujeres, su madre, su hermana, su abuela, la machi), presentando a las figuras masculinas (el padre, el medio hermano) más bien marginales. Se podría decir, en este sentido, que el realizador es una suerte de intruso en este tipo de relato doméstico, asociado tradicionalmente a las mujeres, lo que acentúa su condición de narración al margen de los discursos hegemónicos.

El realizador se mueve entre Francia (donde reside), el sur de Chile (Temuco, donde nació y vivía su abuela) y Venezuela (donde vive su madre) para buscar reconstituir el pasado familiar. Escuchamos por lo tanto diversos idiomas y acentos (el chileno de la familia Ballesteros y el venezolano que ha adquirido su madre), el francés (del entrenador de natación), incluyendo el mapudungun (el realizador visita a una machi para que lo ayude a traer a su madre de regreso, haciendo visible la figura mapuche fuera del contexto de a traer a su madre de regreso, haciendo visible la figura mapuche fuera del contexto de
denuncia o antropológico más tradicional, aunque todavía con cierto grado de exotismo asociado a la sabiduría originaria). Sin embargo, a pesar de dar cuenta de la existencia de este mundo profundamente interconectado, en La Ouemadura no se ven los desplazamientos. El documentalista no exhibe ningún trayecto entre estos lugares, lo que crea la sensación de estancamiento, de paralización. Por ejemplo, las escenas con su hermana o su abuela son de carácter muy íntimo, y muchas de éstas son realizadas con una pequeña cámara de mano que sostiene el realizador en ambientes cerrados y poco luminosos.
Como para contrarrestar esta sensación de empantanamiento, en el montaje emergen las secuencias donde vemos al realizador tomando clases de natación. Sin embargo, aunque el agua podría leerse como una suerte de respiro (tanto para el director como el espectador), o como sanación ante la herida del drama familiar, indica más bien una suspensión. Las tomas son también cerradas y e insisten en la fragmentación del cuerpo. Al igual que las imágenes del sur de Chile, o de los archivos y pasillos de la biblioteca (ambas con la voz en off de la madre), funcionan para dar cuenta de un paisaje interior, porque en este relato, el realizador parece no poder dar cuenta del exterior sino desde su propia subjetividad.

\section{REMITENTE: SOBRE LA TEXTURA DEL OLVIDO}

El documental experimental de Panizza busca reflexionar sobre la memoria y el olvido a través del registro de lo cotidiano, entretejiendo así en su relato las transformaciones de su barrio, el Alzheimer de su abuela y su maternidad, por ejemplo, con la mirada crítica de una sociedad a la deriva, filmando desde las construcciones inmobiliarias de Santiago hasta la muerte de Pinochet. Intenta, por lo tanto, registrar no sólo lo privado pero sus complejas interconexiones con lo público y al mismo tiempo, cuestionar la identidad como algo dado, cristalizado. Así, la realizadora vuelve difusos estos límites moviéndose entre las dos esferas indistintamente, sin ninguna transición y sin otorgar una jerarquía aparente a ninguno de los fragmentos que componen su documental.

Acentuando su postura desde los intersticios, se representa a sí misma como pasajera en tránsito en el mundo actual, en efecto, como "una turista más que ha perdido su city map" nos dice en su documental, y lo hace desde el lenguaje como soporte y como palabra. Lo hace a través de la mezcla de los formatos (sus propias filmaciones se entremezclan con found footage, animaciones gráficas, recortes de papeles, escritos a mano) jugando con los límites del documental y lo hace también a través del uso de múltiple idiomas. La realizadora narra en diferentes lenguas, intercalando inglés y español, incluyendo también palabras en italiano y mapudungun, construyendo así un mundo híbrido, un tejido de voces que logran dar cuenta de un intercambio constante, de una identidad fluida, de un Santiago inserto en el mundo actual, donde la frontera dejó hace tiempo de ser la cordillera de los Andes. A través de la puesta en escena de esta diversidad de lenguas, Panizza pretende dar cuenta a su vez de una "multiplicidad de modos de expresar el mundo" y por lo tanto, de la "imposibilidad de representarlo" a través desde una única mirada. (Entrevista personal, 2010)

Esta elección está estrechamente relacionada con su propia identidad. Como descendiente de inmigrantes, Panizza se considera a sí misma un ser fragmentado, inserto en un país y un continente constituidos a su vez por diversos fragmentos. A través de su trilogía Cartas Visuales, en sí misma un relato hecho por piezas, una suerte de mosaico -la primera, una carta desde Londres a Chile, la segunda, una carta desde Chile a Italia, la tercera carta aún en proceso de definición- quiere dar cuenta de su condición diaspórica de realizadora que habita a la vez diversos mundos, pero siempre enfatizando que, la única posibilidad de dar cuenta de éstos, es desde la propia mirada.

En Remitente, al igual que en La Quemadura, será el sonido el que dará inicio al relato y que vinculará desde sus inicios este ensayo visual con la memoria cultural chilena. Es el sonido de una tradición en extinción, la del afilador de cuchillos, la que trae consigo la imagen de un Chile perdido, como lo hará también el sonido del organillero en otra 
parte de la narración. El texto de Panizza, sobre una elaborada banda sonora (el sonido del agua, de los pájaros, de edificios en construcción, de grabaciones radiales, de música) e imágenes fragmentadas (la bandera, los Andes, las micros amarillas, los edificios de Providencia, habitantes entre la perplejidad y la euforia) buscará construir, desde la asociación y la repetición de imágenes y ruidos, no sólo la textura de la memoria y el olvido sino una propuesta poética del imaginario chileno.

Aquí el uso del comentario tiene un rol preponderante, y será a través de esta narración en voice over de Panizza que Remitente subvertirá el uso de esta estrategia tradicionalmente asociada al sonido autoritario y masculino de la "voz de Dios" (una voz que intenta anclar el significado del texto en los documentales más tradicionales y entregar de este modo verdades universales). El uso de un comentario femenino, nos dice Bruzzi, es subversivo no sólo por el hecho de que sea la voz de una mujer la que hable, sino que también porque es precisamente la especificidad que trae consigo esta voz la que pone de manifiesto la incapacidad del documental de entregar una verdad irrefutable, enfatizando su carácter subjetivo (2000: 58-59).

La presencia de la realizadora es, sin embargo, mucho más incorpórea que material, ya que se la escucha mucho más que se la ve. Sus intervenciones son fragmentadas y mínimas, la vemos como en destellos, como una sombra que afirma una cámara, como una figura a contraluz, como un soporte donde se escriben palabras. Lo que le interesa destacar a Panizza, a través de estas interrupciones explícitas en el documental, es sobre todo la "imposibilidad de representar al otro" (Entrevista personal). La realizadora acentúa así desde la forma misma del documental, el carácter personal y fragmentado de su narración, y su posición desde el exterior de los discursos oficiales y hegemónicos.

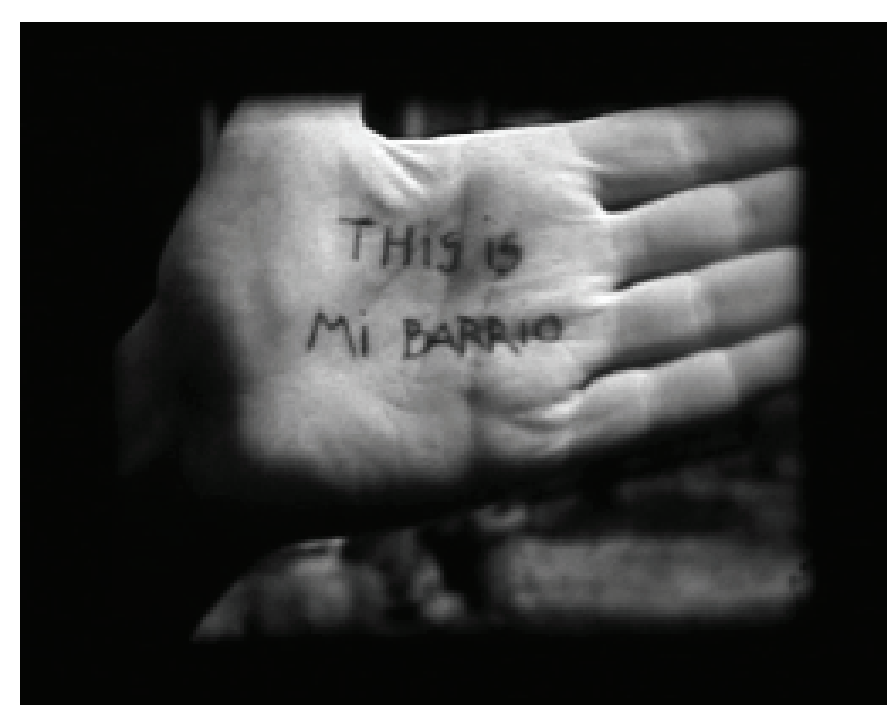

Remitente 3.

En Remitente, la representación de los artificios de la memoria y de su precariedad se $\mathrm{da}$, como decíamos, principalmente desde el lenguaje como soporte, como escritura, como inscripción. Dándole la espalda al formato digital, la realizadora elige la del formato súper
8, el que otorga a las imágenes del Santiago actual la textura de un recuerdo. Es precisamente esta textura la que permite jugar a Panizza con el tiempo y, por lo tanto, con la memoria. El suyo es un ejercicio temprano de nostalgia realizado desde el presente para no olvidar en el futuro. Por eso, se percibe cierto grado de urgencia en su narración, no quiere olvidar lo que sabe que olvidará, porque otros ya lo han hecho (como su abuela, por ejemplo, que ahora "viaja en su máquina del tiempo" o como aquellos que se deshicieron de los recuerdos y ahora son vendidos por docena).

En un acto político cargado de poesía, la realizadora rescata las memorias de desconocidos compradas en el popular mercado Persa Bío-Bío y las convierte en sus propias memorias. A través de home movies (filmaciones caseras) de seres anónimos que han visto convertidos sus recuerdos en algo desechable, en transacción, en parte del mercado actual, ella enumera las cosas que no quiere olvidar. Recordándonos la lista de "las cosas que aceleran el corazón" de la escritora japonesa Sei Shonagon citada en Sans Soleil (Chris Marker 1983). Panizza monta imágenes de hombres filmando o sacando fotos (ella es esos hombres ahora, ella será esos hombres después), de bebés, de mujeres embarazadas o tendidas al sol, de celebraciones, mientras ella enumera sobre estas imágenes su propia lista. Son recuerdos de otros, escribe en la pantalla. Son "mis" recuerdos, corrige luego.

Así advertimos no sólo que es el uso que se le da a las imágenes lo que importa, sino que, siguiendo nuevamente a Kuhn, observamos que la memoria no necesita un testigo, ya que ésta no exige la presencia de quien recuerda en la escena original del hecho para existir (2002: 128). Esto quiere decir que la memoria circula, se desplaza, que la memoria, especialmente ahora, donde las imágenes lo inundan todo, puede ser "prostética" (Landsberg, 1995), incorporada a través de imágenes de otros (fotos, películas, noticias, museos) y no necesariamente adquirida por una experiencia vivida directamente.

Es, precisamente, a través de esta memoria postiza, como construimos y transformamos nuestras propias identidades en la actualidad y es así también como las nuevas generaciones pueden identificase y recordar los hechos de un pasado cultural que no se ha vivido, como el de la dictadura. Por eso, el acto de rescatar la memoria de "otros" de Panizza puede interpretarse como un acto político. El "uso" del material pasa de ser uno comercial a uno evocativo, poético: las fotos son releídas y reconfiguradas en un presente-pasado que las revaloriza (intentando convertirlas -en vano, claro está- otra vez en promesa de un pasado luminoso, aunque ahora desde la nostalgia) como huellas de un historia que nos pertenece a todos.

A la poesía y a la emotividad del logrado montaje del material encontrado en el mercado de las pulgas, Panizza contrasta acto seguido, la dureza del sonido y de imágenes de edificios en construcción que están desplazando a las antiguas edificaciones. Embellece estas imágenes, sin embargo, la presencia de una bolsa de plástico en el aire (poniendo así el acento en la valor de la mirada, en la acción de simplemente mirar), mientras, la voz en inglés de la realizadora enfatiza "Odio olvidar cómo era la casa que estaba aquí". Precisamente, es a través del exceso en estas imágenes, de la presencia incómoda de estas construcciones y del ruido en ellas, por donde se filtran las ruinas de la historia. 


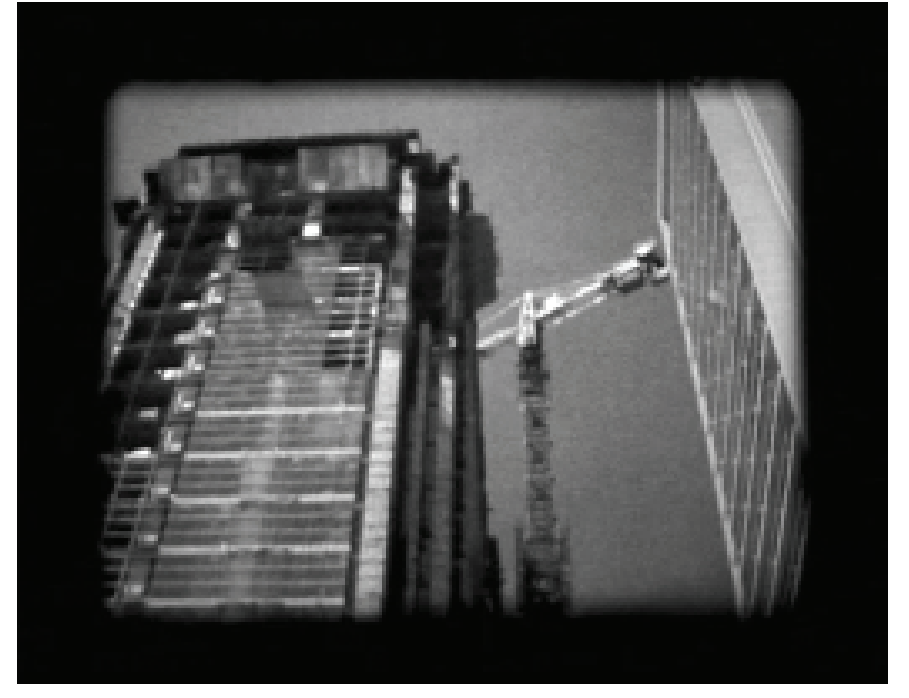

Remitente 1.

Volvemos a ver aquí la imagen del Santiago que se construye, pero que en vez de dar cuenta de un desarrollo sin par en América Latina como pretende el discurso hegemónico, exhibe la ausencia del pasado, de aquello que ya no está y que ha sido hecho desaparecer a punta de fusiles, consensos y centros comerciales. La realizadora representa la capital como una ciudad enferma que difícilmente podrá mejorar, porque el pasado, aunque quiera ocultarse tras la arremetida de las farmacias, de las tinturas para el pelo y las construcciones que buscan convertir Santiago en Nueva York, como nos dice en el comentario, todavía ronda por las calles.

Hay una escena, un segmento en particular, que nos remite directamente a los resabios dictatoriales. Es precisamente, un hito mayor en la historia de Chile y al que Panizza parece asignar la misma importancia que al resto de los fragmentos que constituyen su narración. "Muere Pinochet" nos indica en la pantalla. Luego, escribe: "yo estuve ahí con mi cámara". Panizza da cuenta así de su "doble militancia" como periodista y realizadora audiovisual, mientras defiende en ese estar ahí, en el de gesto de capturar la realidad mientras ésta se genera, la esencia documental de su realización (a pesar de su permanente coqueteo con la ficción).

Dando cuenta del país polarizado de esos días, Panizza se arroja a las calles a filmar las reacciones de los dos Chiles (y a través de esta acción parece hacerle un guiño a la tradición del cine de "trinchera" que la precede). Es el montaje de este fragmento el que nos da cuenta de la confusión de este momento y de la imposibilidad última de representarlo. Sin necesidad de narración, este fragmento está construido a través de un tejido de repeticiones: de la mujer atónita que mira desde la micro, de la enfermera-maniquí y de diversas grabaciones radiales entrecortadas, que se superponen y parecen hablar de fórmulas matemáticas en un lenguaje complejo, ininteligible. ¿Desde qué otro modo sino que desde la inteligibilidad representar aquel gran evento?

Frente al Hospital Militar están los simpatizantes de derecha que sostienen pancartas de apoyo al dictador. La rabia y el odio del pasado remoto, de aquellos enfrentamientos entre "rotos" y "momios", se hace presente en uno de los simpatizantes de derecha congregados frente al hospital, el que nos lleva a recordar a la mujer que pide a gritos el fin de

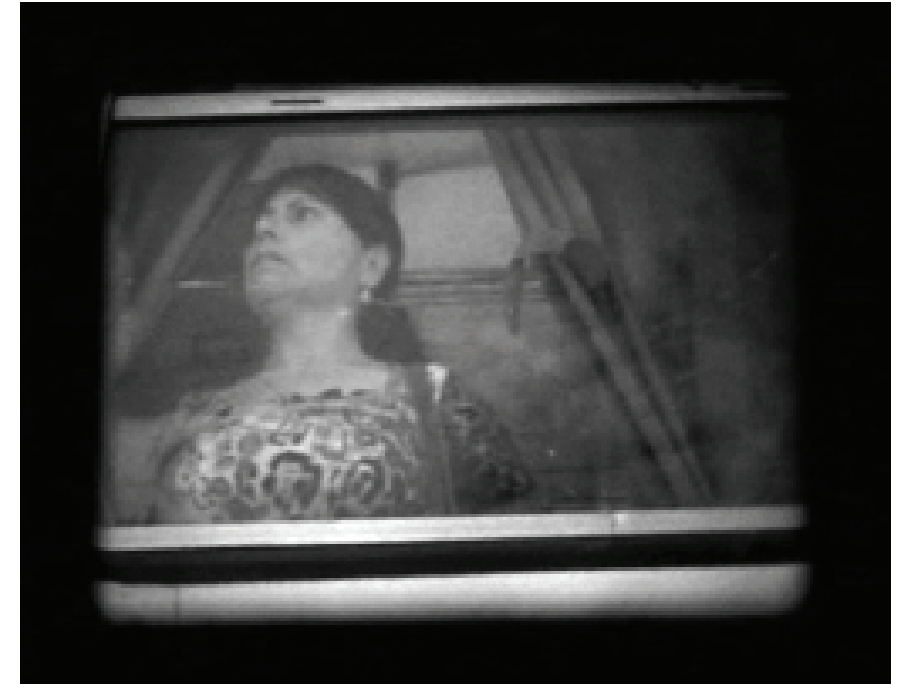

Remitente 2.

la Unidad Popular en una de las famosas escenas de La Batalla de Chile (Primera parte: La Insurrección de la Burguesía (1975)) de Patricio Guzmán ${ }^{12}$.

Aquí no hay sonido directo -no lo hay en efecto en toda la narración, pero la presencia de esta "masa" y el hecho de que el simpatizante de Pinochet se dirige directamente a la directora tras la cámara hace esta ausencia más evidente- ni comentario. Panizza construye una brecha entre esos "otros" y ella, filmando desde fuera, distanciándose de ellos y escribiendo en inglés, como apuntando con un dedo acusatorio "él me dijo perra comunista". Con esta nota escrita en la pantalla ella no sólo se aleja de los pinochetistas, dejando ver la desconfianza contemporánea por la colectividad señalada por Masiello, sino también enfatiza su relación con la historia. Es ella y no otro quien está dando cuenta de aquel instante. Efectivamente, para la realizadora, "los grandes procesos sociales se cuentan desde lo íntimo, a mí me interesa ver esos procesos, esos cambios, desde la esfera íntima. Es, en este sentido, que veo este tipo de relato como única verdad cinematográfica posible" (Entrevista personal, 2010).

Como hemos visto, es sólo desde la confusión que se puede dar cuenta de la dictadura. De hecho, es nuevamente la imposibilidad de representar este pasado lo que pone de manifiesto esta secuencia. Por eso las imágenes del "otro" Chile que celebra la partida de Pinochet en la Plaza Italia, lugar emblemático de encuentro para las celebraciones de carácter popular, son filmadas con la misma distancia y conservan el mismo desconcierto. Por ejemplo, no hay nada que indique que se está en este emblemático lugar más que un recorte inserto en la pantalla. En la escena se entremezclan detalles de pancartas, mujeres envueltas con banderas, bailarinas de carnaval, aunque éstas sean acompañadas con el

12 La mujer de la escena en cuestión exclama: “ $i Q u e ́$ se acuse constitucionalmente al presidente y lo saquen el veintiuno de mayo mismo! ... iPorque tienen destruido, molido, y éste es un gobierno corrompido y degenerado, señor! ¡Degenerado y corrompido! inmundo! iComunistas asquerosos, tienen que salir todos de Chile! El 21 de y sacando a esos comunistas, marxistas podridos... iMalditos sean!"” Citado por Jacqueline Mouesca (1988: 83). 
comentario crítico de la directora relacionado con el avance del sistema neoliberal y los costes del progreso.

Panizza sabía que registrar estas imágenes del Chile dividido era urgente para poder "detener el tiempo, para poder re-pasarlo", como explica (Entrevista). Detenerlo para interrogarlo desde el presente. Urgente, por lo tanto, porque a la distancia, después de cuatro años de la muerte de Pinochet, quedarían estas imágenes para hacernos reflexionar sobre el significado que tienen hoy. Y urgente porque tendrían el valor de recordarnos que las heridas de Chile no se cerrarían con la muerte del dictador, que permanecerían abiertas. Sino ¿cómo explicarnos los bustos de Pinochet circulando por las calles? ¿Cómo explicarnos los acalorados y hasta violentos debates generados por la reciente inauguración del Museo de la Memoria? ¿De qué otra manera explicar estas ruinas o estas ausencias de las que nos hablan estos documentales?

A través del análisis de estas realizaciones, caracterizadas principalmente por la puesta en escena de la ausencia y la fragmentación, hemos pretendido indagar en los modos de recordar que presenta una nueva generación de documentalistas trabajando durante la post-dictadura. Dejando de lado la temática de las violaciones a los derechos humanos las representaciones de proyectos colectivos, estos documentalistas hacen visible desde la subjetividad de sus peculiares relatos autobiográficos las interconexiones entre la esfera privada y el pasado reciente que comparte la nación.

Desde el cuestionamiento de la identidad como algo fijo, se plantean como personajes en tránsito, confundidos y perplejos en medio de un mundo interconectado y las transformaciones que vive la sociedad chilena contemporánea, que debe convivir entre las ruinas del pasado y el progreso que amenaza con cubrirlas para siempre a un ritmo vertiginoso. Para no olvidar, estos documentalistas dan cuenta, precisamente, de la imposibilidad de no hacerlo.

Es así como estas narraciones se configuran desde los márgenes y desde la imposibilidad, fuera de los discursos binarios sobre olvido y memoria, sin idealizar el pasado como monumento, lejos de los rituales conmemorativos y más cerca de las ruinas, más allá de discurso del progreso y de las ventajas de vivir en un mundo "sin fronteras". Lejos de la historia como evento, de la narración épica (no hay cabida en estos relatos para las imágenes de archivo del pasado político reciente, pero sí para las memorias “caseras”), el acento lo ponen en cuestionar los artificios de la memoria. La memoria para ellos parece no ser evidencia de nada, sino más bien una estrategia que permite indagar en el pasado, no como algo estable sino como algo que se va reconfigurando en el presente, pero que, sin embargo, se escabulle y que es, finalmente, imposible de representar. El pasado no es idealizado en estos relatos, no hay lugar en este presente para aquello, la historia (ahora sí, como evento) parece haberles enseñado que no hay un pasado más luminoso en el futuro.

\section{REFERENCIAS}

Amado, Ana. (2009/2010). “Memory, Identity and Film. Blending Past and Present”. Revista Harvard Review of Latin America, David Rockefeller Center for Latin America Studies VIII: $38-41$.

Avelar, Idelber. (2001). Five Theses on Torture. Journal of Latin American Cultural Studies 10: 253-271.

Borghino, Christian. (2010). "La Quemadura. René Ballesteros (Entrevista)” Réel 03. Journal du Festival Cinema du Réel.

Bruzzi, Stella. (2000). New Documentary: A Critical Introduction. London: Routledge.
Chanan, Michael. (2003) “El Documental y la Esfera Pública en América Latina”. Notas sobre la Situación del Documental en América Latina (comparada con cualquier otro sitio). Secuencias. Revista de Historia de Cine 18: 22- 32.

Hirsch, Marianne. (1997). Family Frames: Photography, Narrative, and Postmemory. Cambridge, Mass: Harvard University Press.

—. (1999). "Projected Memory: Holocaust Photographs in Personal and Public Fantasy". En Mieke Bal, Jonathan Crewe y Leo Spitzer (eds.), Acts of Memory. Cultural Recall in the Present (pp. 3- 23). Hanover, London: Darmouth College.

Huyssen, Andreas. (2000). “Present Pasts: Media, Politics, Amnesia”, Public Culture 12 (1): 21-38

Jelin, Elizabeth. (2001). Memorias de la Represión Vol. 1: Los trabajos de la memoria. Madrid: Siglo XXI Editores.

Kaplan, E. Ann. (2005). Trauma Culture. The Politics of Terror and Loss in Media and Literature. New Brunswick, New Jersey, London: Rutgers University Press.

Kuhn, Annette. (2002) Family Secrets: Acts of Memory and Imagination. 2a ed. London: Verso Lazzara, Michael J. (2009) "Filming Loss: (Post-) Memory, Subjectivity, and the Performance of Failure in Recent Argentine Documentary Films". Latin American Perspectives 36 (5): 147-157.

Landsberg, Alison. (1995). "Prosthetic Memory: Total Recall and Blade Runner". En Mike Featherstone, Roger Burrows en Cyberspace / Cyberbodies / Cyberpunk: Cultures of Technological Embodiment (pp. 175-189). London, Thousand Oaks, New Delhi: SAGE Publications.

Masiello, Francini. (2001). The Art of Transition. Latin American Culture and Neoliberal Crisis. Durham, London: Duke University Press.

Mouesca, Jacqueline. (2005). El documental chileno. Santiago: LOM.

-. (1988). Plano Secuencia de la Memoria de Chile. Veinticinco años de Cine Chileno (1960-1985). Madrid: Ediciones del Litoral.

Moulian, Tomás. (2002). Chile Actual: Anatomía de un Mito, 3ra ed. Santiago: LOM.

Nouzeilles, Gabriela. (2005). "Postmemory Cinema and the Future of the Past in Albertina Carri's Los Rubios". Journal of Latin American Cultural Studies, 14: 263-278.

Pinto, Iván. (sin fecha). "Cine, Política, Memoria. Nuevos Entramados en el Documental Chileno". Dossier Documental en Chile. Revista de Cine La Fuga. Obtenido el 6 de Enero del 2010 desde http://lafuga.cl/cine-politica-memoria/341.

Rich, Ruby. (1997). "An/Other View Of New Latin American Cinema”. En Michael T. Martin (ed). New Latin American Cinema. Volume One. Theory, Practices and Transcontinental Articulations. (pp. 273- 297). Detroit: Wayne State University Press.

Richard, Nelly. (2000). "The Reconfigurations of Post-dictatorship Critical Thought", Journal of Latin American Cultural Studies 9: 273- 282.

Wilde, Alexandre. (1999). "Irruptions of Memory: Expressive Politics in Chile's Transition to Democracy". Journal of Latin American Studies 31: 473-500.

Entrevistas:

Ballesteros, René. (2010). Entrevista personal con el documentalista realizada el 29 de abril 2010 (vía email).

Panizza, Tiziana. (2010). Entrevista personal con la documentalista realizada el 28 de abril 2010 (vía telefónica).

Recepción: martes 15 de septiembre de 2009 Aceptación: jueves 7 de enero de 2010 